\title{
REDES E GRUPOS DE PODER EM PRESIDENTE PRUDENTE - SP: ANÁLISE A PARTIR DAS ELEIÇÕES MUNICIPAIS
}

Rafael Freire de Paula ${ }^{1}$ Márcia da Silva²

Resumo: A presença de determinados grupos de poder na administração local em Presidente Prudente - SP resulta na predominância de seus interesses econômicos e políticos, bem como seu envolvimento com partidos políticos e disputas eleitorais. Essa pesquisa teve como objetivo identificar os grupos de poder, as estratégias utilizadas para a manutenção de seus interesses e as relações de poder que os grupos mantêm entre si em forma de redes de poder. A investigação das características dos grupos de poder, bem como das estratégias utilizadas pelos mesmos, cuja finalidade é assegurar seus interesses, fazem-se importantes para discutirmos as disputas eleitorais na democracia brasileira, os setores econômicos e políticos nelas envolvidos e os resultados ou rebatimentos territoriais desse processo. Identificou-se vinculações e conexões que se constroem a partir de redes de poder e um processo de reorganização que envolve os agentes políticoterritoriais que compõem os grupos de poder investigados.

Palavras-chave: Território. Agentes Político-Territoriais. Redes de Poder.

\section{NETWORKS NA POWER GROUPS IN PRESIDENTE PRUDENTE - SP: ANÁLISIS FROM MUNICIPAL ELECTIONS}

Abstract: The presence of certain power groups in local administration in Presidente Prudente - SP results in the predominance of their economic and political interests, as well their involvement with political parties and electoral disputes. This research aims to identify the power groups, the strategies used for maintaining their interests and the power relationships that groups, maintain among themselves in the form of power networks. The research of the characteristics of the power groups and the strategies used by them, whose purpose is to ensure their interests, are important to discuss the electoral disputes in Brazilian democracy, the economic and political sectors involved and the results or the territorial rebeatings of this process. Links and connections were identified which are constructed from power networks and a reorganisation process involving the political and territorial agents that comprise the groups of power investigated.

Keywords: Territory. Politics-Territorial agents. Power Networks.

\section{REDES Y GRUPOS DE PODER EN PRESIDENTE PRUDENTE - SP: ANÁLISIS A PARTIR DE LAS ELECCIONES MUNICIPALES}

Resumen: La presencia de determinados grupos de poder en la administración local en Presidente Prudente - SP resulta en la predominancia de sus intereses económicos y políticos, así como su implicación con partidos políticos y disputas electorales. Esta investigación tuvo como objetivo identificar los grupos de poder, las

\footnotetext{
${ }^{1}$ Universidade Estadual do Centro-Oeste, UNICENTRO, Guarapuava-PR, Brasil, freire_depaula@yahoo.com, https://orcid.org/0000-0002-8160-9357.

2 Universidade Estadual do Centro-Oeste, UNICENTRO, Departamento de Geografia, GuarapuavaPR, Brasil, marcia.silvams@gmail.com, http://orcid.org/0000-0002-2742-1396.
} 
estrategias utilizadas para el mantenimiento de sus intereses y las relaciones de poder que los grupos mantienen entre sí en forma de redes de poder. La investigación de las características de los grupos de poder, así como de las estrategias utilizadas por los mismos, cuya finalidad es asegurar sus intereses, se hacen importantes para discutir las disputas electorales en la democracia brasileña, los sectores económicos y políticos en ellas involucrados y los resultados 0 consecuencias territoriales de este proceso. Se identificaron vinculaciones y conexiones que se construyen a partir de redes de poder y un proceso de reorganización que involucra a los agentes político-territoriales que componen los grupos de poder investigados.

Palabras clave: Territorio. Agentes Político-Territoriales. Redes de Poder.

\section{Introdução}

O crescimento de Presidente Prudente - SP, inicialmente, possui vinculação direta com o fatiamento dos fragmentos da Fazenda Pirapó-Santo Anastácio, no Pontal do Paranapanema, movimentando o emergente mercado de terras e a também crescente especulação no preço da terra principalmente após a década de 1930 (LEITE, 1998).

Junto ao dinamismo do mercado de terras griladas e comercializadas em Presidente Prudente ocorrem emancipações de vários municípios do Pontal, que de pertencentes a Presidente Prudente, passam, por diversos motivos, a serem autônomos do ponto de vista político administrativo. À medida que se criavam novos municípios, verificou-se que "frequentemente o poder político passava a pertencer ao coronel fazendeiro" (LEITE, 1998, p.48). Em Presidente Prudente confirmou-se essa tese, afinal, a presença direta das famílias Marcondes e Goulart ${ }^{3}$ é recorrente nas seguidas composições da casa legislativa desde a fundação do município até meados da década de 1950,

Nesse contexto, o município de Presidente Prudente é marcado por estruturas de poder político cuja posse e/ou liderança política ao longo dos anos esteve, em maioria, ligada a famílias tradicionais, empresários locais e proprietários rurais (latifundiários). A liderança política exercida por esses grupos nos instigou a realizar uma pesquisa a respeito da formação e atuação dos grupos de poder político em seus respectivos períodos de gestão, bem como nas disputas eleitorais dentro do

\footnotetext{
${ }^{3}$ O Coronel Francisco de Paula Goulart ocupou, após herança, a fazenda Pirapó-Santo Anastácio e foi agente importante no mercado de terras da região, assim como José Soares Marcondes, vinculado a demarcação e comercialização de lotes nas proximidades da linha férrea durante o processo de urbanização de Presidente Prudente - SP (MELO, 1996).
} 
recorte temporal proposto (pós-redemocratização do país), que envolve, consequentemente, alianças partidárias ou intergrupos de poder construídas.

A ação política de um gestor é complexa, pensemos, por exemplo, em um prefeito municipal: suas decisões políticas e administrativas são resultantes de uma correlação de forças, tomadas a partir do embate entre o indivíduo (gestor), orientação partidária, empresariado, partidos aliados, acordos com oposicionistas e também da participação da sociedade. Desse modo, não há como interpretar as ações do poder público apenas do ponto de vista partidário (partido governista) ou individualista, no caso, na perspectiva do prefeito municipal, mas sim, considerando a complexa teia de interesses divergentes e convergentes existentes no ambiente político, que se reflete nas redes de poder.

O objetivo da pesquisa foi, a partir do resgate do constructo político de Presidente Prudente/SP, identificar as ações dos grupos de poder no município (administrações e coligações), sua organização em redes de poder, as características do poder político local, bem como identificar as estratégias utilizadas pela elite local para sua manutenção do poder, tendo como recorte temporal o período pós-redemocratização do país (1985), devido ser este o período onde há o multipartidarismo e eleições diretas por sufrágio universal.

A realização deste trabalho justifica-se devido a dois fatores principais, são eles: o entendimento do interior dos grupos de poder, no intuito de observar os diversos rebatimentos territoriais nas disputadas oriundas das decisões por eles tomadas; e o controle de estruturas de manutenção do poder político e manipulação da opinião pública (a elite em ação), como a posse de canais de TV, rádio e o uso do poder simbólico. Uma vez que se buscou a investigação das formas de controle, perpetuação e as vinculações entre os agentes político-territoriais que compõem os grupos de poder, temos outra problemática - presente como plano de fundo dessa pesquisa - que é a fragilidade da real participação popular e, consequentemente, da democracia, haja vista os direcionamentos políticos traçados nos bastidores do poder local.

Considerando os objetivos e argumentos expostos acima, este artigo visa divulgar os principais resultados dessa pesquisa, em nível de mestrado, relativos a identificação dos grupos de poder e os agentes político-territoriais que os compõem, as estratégias político-partidárias e de poder utilizadas por estes grupos com intuito de reproduzirem-se social e politicamente, a configuração das redes de poder e o processo de reorganização de viés conservador em curso. 


\section{Materiais e métodos}

Para responder as questões da pesquisa presentes nos objetivos citados anteriormente, relativas ao comportamento e as estratégias dos grupos de poder, houve a seleção de procedimentos metodológicos que assegurassem a coerência das análises e, posteriormente, a veracidade dos resultados encontrados e conclusões tomadas a partir deles.

De início, foram definidos os principais conceitos que trabalhamos nesta pesquisa, a saber: poder local, com destaque as abordagens de Kerbauy (2007), Silva (2014) e Vainer (2001); grupos de poder (Silva, 2014); e território, cuja maior ênfase está, nessa pesquisa, em Raffestin (1993), Fernandes (2013), Santos (2006) e Souza (2012).

A partir dos conceitos, que podem expressar a realidade ou parte dela, guardadas as especificidades, houve o desafio de identificar e caracterizar os principais grupos de poder envolvidos nas disputas eleitorais no município de Presidente Prudente. A denominação dos grupos, dando-lhes identidade, foi realizada a partir da análise dos dados dos pleitos eleitorais entre 1988 e 2016, sendo parte deles coletados junto ao jornal O Imparcial e, a partir dos anos 2000, junto à base de dados do Tribunal Superior Eleitoral - TSE. Tivemos acesso à primeira fonte citada no arquivo histórico do Museu Municipal de Presidente Prudente, enquanto aos dados do TSE, foi necessária a utilização do software Excel para manusear os resultados eleitorais do recorte temporal que propusemos.

Os grupos de poder foram organizados e separados com base nas entrevistas semiestruturadas, nos posicionamentos dos entrevistados e/ou citados nas mesmas, bem como nas análises das disputas eleitorais dentro do recorte temporal proposto e a atuação dos agentes político-territoriais no período. Essas entrevistas, com um roteiro de questões prévias, mas com variações de acordo com o entrevistado e/ou andamento das falas dos mesmos (COLOGNESE; MELLO, 1998), proporcionou compreendermos as disputas intergrupos de poder, o deslocamento de agentes político-territoriais de um grupo para outro, as rivalidades intragrupos de poder e, ainda, discutir processos em curso relativos aos grupos investigados, como aquele que reúne aspectos de uma reorganização conservadora.

O roteiro prévio foi elaborado com questões comuns e outras específicas para cada um dos entrevistados. Como analisamos um recorte temporal longo (1988- 
2016), alguns dos entrevistados não vivenciaram todo esse período, desse modo, as questões foram adaptadas de acordo com a atuação temporal do entrevistado, bem como sua função política, papel de centralidade ou não no poder político local, o grupo ao qual pertence e função pública que ocupava no momento da entrevista (se ocupante).

De modo geral, as questões estavam relacionadas: (i) a formação política do entrevistado e sua trajetória; (ii) as disputas envolvendo o poder político local que vivenciou (seja como prefeito, candidato, vereador ou deputado); (iii) a atuação do partido ao qual o entrevistado está (ou esteve) inserido e a lógica do mesmo para o estabelecimento de coligações para eleições municipais; (iv) o apontamento de adversários e daqueles mais próximos; $(v)$ a reflexão a respeito de grupos políticos existentes em Presidente Prudente e a força política dos mesmos (respeitando o tempo especialmente nesses dois últimos itens, pois na política as alianças e adversidades surgem e desaparecem rapidamente); (vi) a avaliação do cenário nacional e estadual e os rebatimentos das outras esferas políticas nas disputas locais; e (vii) as situações pontuais que o pesquisador necessita de esclarecimento.

Foram realizadas oito entrevistas: Adilson Silgueiro, ex-vereador pelo PMDB e cassado em 2016; André Ferreira, candidato a vice-prefeito pelo PSOL - Partido Socialismo e Liberdade em 2016; Ed Thomas, deputado estadual pelo PSB - Partido Socialista Brasileiro; Fábio Sato, candidato do PPS - Partido Popular Socialista nas duas últimas eleições para prefeito, com resultados eleitorais expressivos; José Lemes Soares, candidato ao cargo de prefeito em 2016 pelo PRB - Partido Republicano Brasileiro; Mauro Bragato, dirigente regional do PSDB - Partido da Social Democracia Brasileira - , ex-prefeito de Presidente Prudente e ex-deputado estadual por vários mandatos antes e durante nosso recorte temporal; Regina Penati, ex-vereadora e candidata ao cargo de prefeita em 2016 pelo PT - Partido dos Trabalhadores; e Nelson Bugalho, candidato vitorioso para o cargo de prefeito pelo PTB - Partido Trabalhista Brasileiro.

Os entrevistados permitiram, via documentação, a utilização de seus nomes, sendo desnecessária a utilização de qualquer tipo de linguagem codificada. Entretanto, nem todos os possíveis entrevistados nos atenderam ${ }^{4}$. A opção pelos

\footnotetext{
${ }^{4} \mathrm{O}$ planejamento inicial era de entrevistar também outros atores políticos: Alba Lucena, vereadora por seis mandatos consecutivos, inclusive o atual, mas que não respondeu as nossas tentativas de contato (redes sociais, e-mail da Câmara e e-mail institucional de docente na Universidade do Oeste Paulista - UNOESTE); Agripino de Oliveira Lima, ex-prefeito por três mandatos e elemento chave na pesquisa, que não nos retornou em razão de fragilidades na saúde oriundas da idade avançada que culminaram com seu falecimento no início de 2018 e; Paulo Lima, filho de Agripino Lima, gestor das
} 
nomes citados tem relação com diferentes variáveis, como a presença dos mesmos nos últimos pleitos eleitorais, histórico partidário e de alianças, a atuação na Câmara (quando vereadores), relação direta com relevantes grupos econômicos e ligações institucionais ou com movimentos sociais.

O conteúdo das entrevistas foi analisado de maneira que os dados coletados pudessem ser utilizados com segurança e veracidade. Para tanto, verificou-se as afirmações sobre os temas das perguntas para todos os entrevistados, resultando em situações onde o entrevistado A, B, C e D, pertencentes a grupos de poder distintos, afirmaram argumento idêntico ou semelhante ao analisar uma conjuntura de aliança ou de rompimento ou, por outro lado, circunstâncias onde apenas um entrevistado afirmou determinada situação, não corroborada por nenhum outro.

Desse modo, construir conjecturas com base na fala de vários entrevistados dá maior segurança ao pesquisador do que confiar em um ou outro entrevistado fielmente, seja por motivação pessoal ou ideológica. Permite, ainda, perceber os pormenores e identificar indícios importantes, algo valioso para pesquisas nas ciências humanas, como aponta Ginzburg (1989), bem como preenchem lacunas derivadas das questões relativas àqueles que optaram em não ceder entrevistas.

As entrevistas semiestruturadas constituíram a base para as representações do índice de conexão em rede entre os agentes político-territoriais em sociogramas, ou seja, situações de proximidade indicam que os mesmos pertencem ao mesmo grupo de poder ou são agentes que intermedeiam as relações entre diferentes grupos de poder, definindo, portanto, a configuração em rede das relações de poder entre os agentes político-territoriais investigados.

Para discutir o exposto acima junto à centralidade característica de alguns agentes político-territoriais, houve a definição, a partir das contribuições dos próprios entrevistados, das variáveis responsáveis pela aproximação ou distanciamento entre os agentes investigados, considerando peso numérico positivo ou negativo para cada uma delas (Quadro 1).

Quadro 1:Critérios para mensuração das conexões entre os agentes políticoterritoriais investigados

empresas da família, ex-deputado federal e vice-prefeito de Presidente Prudente em 2012, que também não retornou nenhuma das formas de contato (redes sociais, e-mail e telefonemas a atendente do Grupo Paulo Lima). A opção pelos nomes citados tem relação com diferentes variáveis, como a presença destes nos últimos pleitos eleitorais, o histórico partidário e de alianças, a atuação na Câmara (quando vereadores) e as ligações institucionais ou com movimentos sociais (como as candidaturas do PT e do PSOL em 2016). 


\begin{tabular}{|c|c|c|}
\hline Variável & $\begin{array}{l}\text { Pon } \\
\text { tos }\end{array}$ & Justificativa \\
\hline 1. Família & 10 & $\begin{array}{l}\text { O vínculo familiar obviamente é o nível máximo de } \\
\text { relacionamento, ainda mais nos casos que temos nessa } \\
\text { pesquisa, referentes a matrimônios ou paternidade. }\end{array}$ \\
\hline $\begin{array}{l}\text { 2. Sócios em } \\
\text { empresas }\end{array}$ & 10 & $\begin{array}{l}\text { A vinculação empresarial está classificada em nível elevado, } \\
\text { pois enquanto sócios, naturalmente os agentes caminham } \\
\text { em direções semelhantes, haja vista a similaridade de seus } \\
\text { interesses. }\end{array}$ \\
\hline $\begin{array}{l}\text { 3. Mesmo partido } \\
\text { atualmente }\end{array}$ & 8 & $\begin{array}{l}\text { A vinculação partidária está como segundo nível de } \\
\text { importância por conta da unidade partidária e das diretrizes } \\
\text { normativas de cada partido. Se houver uma rivalidade entre } \\
\text { membros do mesmo partido, o item } 8 \text { descontará pontos } \\
\text { dessa variável. }\end{array}$ \\
\hline 4. Coligação atual & 5 & $\begin{array}{l}\text { A coligação atual tem maior peso devido sua } \\
\text { contemporaneidade e por representar o novo arranjo político } \\
\text { de Presidente Prudente, o que permite, ainda, pensar } \\
\text { adiante. }\end{array}$ \\
\hline $\begin{array}{l}\text { 5. Relacionamento } \\
\text { pessoal }\end{array}$ & 5 & $\begin{array}{l}\text { O relacionamento pessoal é de média importância pois } \\
\text { existem outras variáveis que fazem com que um agente } A \\
\text { apoie } \mathrm{B} \text { e não } \mathrm{C} \text {, como a decisão institucional do partido ao } \\
\text { qual está vinculado o aqente. }\end{array}$ \\
\hline $\begin{array}{l}\text { 6. Mesmo partido } \\
\text { em eleições } \\
\text { anteriores }\end{array}$ & 3 & $\begin{array}{l}\text { A presença em um mesmo partido em eleições anteriores } \\
\text { detém menor importância, devido a diferentes fatores, como } \\
\text { motivos que levaram à saída de algum agente do partido, } \\
\text { rompimentos internos e a própria infidelidade partidária, } \\
\text { característica do sistema partidário brasileiro. }\end{array}$ \\
\hline $\begin{array}{l}\text { 7. Coligações } \\
\text { anteriores }\end{array}$ & 2 & $\begin{array}{l}\text { Coligações anteriores, assim como no item } 6 \text {, podem mostrar } \\
\text { alguns ranços do agente em análise, portanto, demos um } \\
\text { peso um pouco menor para este item se comparado ao item } \\
6 \text { porque estar numa coligação é de menor unidade do que } \\
\text { estar no mesmo partido. }\end{array}$ \\
\hline $\begin{array}{l}\text { 8. Disputas } \\
\text { intrapartidárias }\end{array}$ & -2 & $\begin{array}{l}\text { A rivalidade intrapartidária descontará pontuação, ainda que } \\
\text { levemente, pois partimos do pressuposto que a rivalidade é } \\
\text { interna ao partido, mas que agentes rivais também atuam } \\
\text { juntos institucionalmente, dada as diretrizes e interesses } \\
\text { partidários que transcendem a escala municipal. }\end{array}$ \\
\hline $\begin{array}{l}\text { 9. Disputas no } \\
\text { âmbito pessoal }\end{array}$ & -4 & $\begin{array}{l}\text { Inimizades ou mesmo rivalidades sérias terão uma alta } \\
\text { pontuação descontada, pois podem levar um agente a } \\
\text { romper partidariamente, manifestar-se publicamente e de } \\
\text { maneira enfática contra seus adversários, rompimentos de } \\
\text { várias ordens ou demais atos que claramente apontam para } \\
\text { rivalidades pessoais }\end{array}$ \\
\hline
\end{tabular}

Org.: Paula (2018).

Ao verificar a pontuação que conecta os agentes investigados, foram elaborados três índices de conexão: baixo, quando menor ou igual a 6 pontos; médio, entre 7 e 14 pontos, e alto, acima de 15 pontos. Essa forma de tratamento dos dados propicia observarmos os agentes político-territoriais que são mais ou menos próximos uns dos outros, pois indica os elos pessoais, de classe e/ou institucionais que os mesmos possuem entre si.

Aliado a isso, e também para compreender melhor os papéis de centralidade desempenhados por alguns dos agentes político-territoriais, realizou-se um levantamento da base material dos grupos de poder com ênfase às empresas cujos 
proprietários estão entre os agentes investigados ${ }^{5}$. Posteriormente, utilizou-se o software Arcgis 10.3 para mapear os municípios onde estão presentes empresas ligadas diretamente aos grupos de poder, demonstrando, assim, o alcance desses grupos e sua importância para além da escala municipal.

Após a elaboração das planilhas com os respectivos dados a respeito das relações entre os agentes político-territoriais investigados nessa pesquisa, 0 software Ucinet/Netdraw foi utilizado para construir a síntese das relações entre e intergrupos de poder em rede, afinal, segundo Santos (2014, p.262) "a rede é também social e política, pelas pessoas, mensagens e valores que a frequentam. Sem isso, e a despeito da materialidade com que se impõe aos nossos sentidos, a rede é, na verdade, uma mera abstração".

Desse modo, a utilização das redes para analisarmos os grupos de poder fezse fundamental porque nos permite compreender, juntos, os diferentes elementos do fenômeno pesquisado, como a materialidade dos grupos, as relações de poder, a questão do poder simbólico e da proximidade ou não entre os agentes políticoterritoriais (rede social e política), que resultam em práticas viciadas do poder público em suas ações no territórios, seja via obras ou políticas públicas, comprometidas em demasia com os interesses dos grupos de poder e suas bases.

\section{Resultados e discussão}

Distinguiu-se grupos de poder de agentes político-territoriais devido ao fato de que a atuação política de instituições e/ou indivíduos nem sempre são via grupos, ou seja, a análise através dos agentes político-territoriais permite a observação de atores e instituições diversas que atuam política e territorialmente, compõem e alteram grupos de poder distintos no tempo e no espaço. Em síntese, a análise a partir dos agentes político-territoriais permite alcançar instituições de classe e também aquelas relacionadas ao poder simbólico.

A partir da análise dos dados das eleições municipais entre 1988 e 2016, nos quais observou-se o comportamento político-eleitoral dos agentes político-territoriais investigados na pesquisa, bem como das entrevistas semiestruturadas, o primeiro passo foi desvendar os grupos de poder e os agentes que os compõem:

\footnotetext{
${ }^{5}$ Tivemos imensa dificuldade neste ponto devido ao fato de que apenas recentemente dados sobre bens de candidatos e despesas de campanha são divulgados pelo TSE.
} 
Figura 1: Grupos de poder e agentes político-territoriais
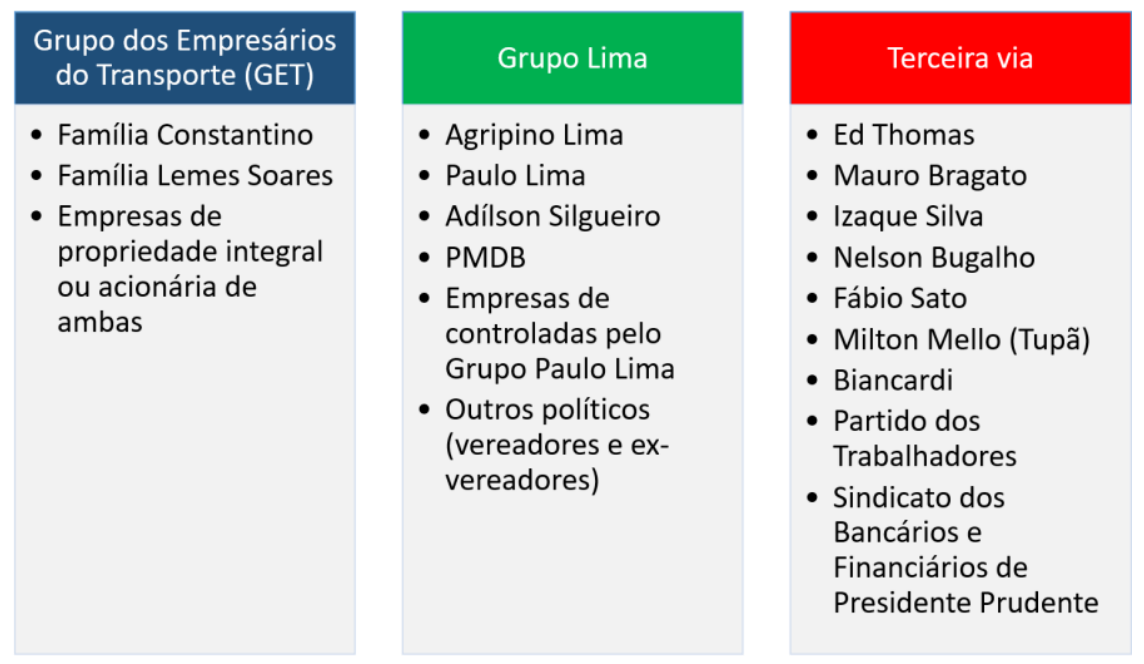

O Grupo Lima se apresenta a partir das duas lideranças principais, mas distintas em suas formas de ação política: Agripino Lima e Paulo Lima, pai e filho respectivamente. Agripino Lima foi deputado constituinte, prefeito eleito por três vezes, com mandatos cumpridos entre 1993-1996, 2001-2004 e 2005-2007 (cassado ao meio do mandato neste último). Paulo Lima foi eleito deputado federal nas eleições de 1994, 1998 e 2002, mas não conseguiu vencer outras eleições para nenhum dos cargos pleiteados após este período.

Todavia, não se deve restringir este grupo apenas a ótica familiar ou observar suas ações e/ou presença localmente, seria simplificá-lo e condená-lo ao enfraquecimento e/ou desaparecimento a partir do distanciamento de um ou ambos do cenário político direto, isto é, candidatando-se. A importância do Grupo Lima para compreendermos as disputadas arraigadas no território foi apontada por Fábio Sato:

O Agripino, ele gerou boa parte dos outros grupos políticos né, dessa nova geração, dos últimos 30 anos em Prudente, podemos dizer que o Agripino foi a grande matriz geradora dos políticos, muitos dos que estão em atividades hoje surgiram na sua base (FÁBIO_SATO_36).

Viu-se, portanto, que Agripino Lima, mesmo com Paulo Lima como seu principal herdeiro político, não exerceu sua ação política direta apenas junto ao filho, mas investiu em diversos outros agentes ao longo de sua vida política. Assim como o entrevistado citado acima salientou, vários dos políticos que atuam nas eleições

\footnotetext{
${ }^{6}$ Transcrevemos todas as entrevistas e organizamos a mesma segunda a fala dos entrevistados. Desse modo, a referência "FÁBIO_SATO_3 " indica que a fala usada como citação direta está presente na terceira fala do candidato para nossa entrevista. Esse modelo de organização auxiliou na transcrição dos áudios e pode ser importante caso as entrevistas sejam revisitadas.
} 
prudentinas possuem sua gênese em Agripino Lima, tais como: Biancardi, Adilson Silgueiro, Ed Thomas e Milton Mello - Tupã.

Biancardi, Ed Thomas e Tupã, atualmente, compõem a Terceira via, pois, muito embora tenham surgido no seio do Grupo Lima, ocorreram conflitos internos cujo resultado foi um processo de reorganização onde tais agentes políticoterritoriais buscaram outros caminhos para sua atuação político-partidária.

Verificou-se os motivos que levaram ao rompimento entre Biancardi e Agripino Lima na fala de Adilson Silgueiro, quando o entrevistado avalia a posição de candidato a vice-prefeito de Biancardi e lembra o cenário de disputa nas eleições de 2008:

[...] o Biancardi já tinha sido vice do Tupã, aliás, do Agripino, houve uma briga porque o Agripino queria que ele renunciasse quando ele foi cassado e ele não renunciou, e depois ele acabou tendo um rompimento com o Tupã, o Tupã era secretário de obras dele, ele mandou o Tupã embora e o Tupã veio disputar para prefeito com o Agripino e ele ganhou a eleição (ADILSON_SILGUEIRO_5).

Quando Tupã, presente na citação acima, é eleito prefeito, ocorre em seguida uma reorganização dos grupos de poder a partir de um conflito no seio do Grupo Lima, "a briga toda foi por causa do Paulo Lima [...], a briga não foi do Tupã com o Agripino, a briga foi Tupã e Paulo, e aí acaba respingando no Agripino" (ADILSON_SILGUEIRO_2).

Para o entrevistado "[...] Paulo Lima é um cara complicado, eu acho o Paulo Lima um cara inteligentíssimo, ele tem uma experiência grande [...], mas ele é um cara que quer tudo para ele" (ADILSON_SILGUEIRO_2), tal caracterização também aparece em meio a falas de Regina Penati quando a mesma avalia o distanciamento do prefeito eleito em 2008, Tupã, em relação ao Grupo Lima "Esse rompimento ocorre já no primeiro mandato. Umas questões até pelas características do Paulo Lima e tal" (REGINA_PENATI_3), bem como na contribuição de outro entrevistado, Ed Thomas:

[...] O mal ainda dos nossos partidos são os caciques, são os proprietários, eu não aceitava muito isso de maneira nenhuma. Eu estava eleito deputado estadual. O partido é um instrumento que nos faz chegar a um cargo e a uma posição, que é a do gestor político, mas o PMDB não compreendia assim, tanto é que eu tive problemas com o PMDB Presidente Prudente, não com o PMDB estadual, nem o PMDB nacional, eu não ia obedecer a ordens de um PMDB ou de 
um proprietário do partido na minha cidade, na minha região, de jeito nenhum (ED_THOMAS_3).

Tais contribuições endossam o argumento de que Paulo Lima, mesmo em declínio eleitoral direto, isto é, não ter conseguido eleger-se nos últimos pleitos, mantém forte presença nos bastidores político-partidários em Presidente Prudente, delineando alianças e sendo pivô de conflitos que envolvem o Grupo Lima.

Tal poder se sustenta no aspecto econômico (Tabela 1), algo que verificamos a partir da divulgação de bens à Justiça Eleitoral como requisito para candidatura às eleições municipais de 2012. Naquele ano Paulo Lima foi candidato a vice-prefeito em chapa com Agripino Lima, que também possui base material/financeira relevante, o que reforça a obtenção de outras formas de poder, como o ideológico e o simbólico.

Tabela 1: Declaração de bens materiais de Agripino (2016) e Paulo Lima (2012) a Justiça Eleitoral

\begin{tabular}{|c|c|c|c|c|}
\hline \multicolumn{5}{|c|}{ Bens Declarados ao TSE por membros do Grupo Lima } \\
\hline CATEGORIA & & AULO LIMA & AGF & IPINO LIMA \\
\hline Casas e apartamentos & $R \$$ & 1.578.836,07 & $\mathrm{R} \$$ & 0,00 \\
\hline Terrenos & $R \$$ & $492.661,37$ & $R \$$ & 0,00 \\
\hline Veículos & $R \$$ & $605.140,06$ & $R \$$ & 0,00 \\
\hline Propriedades rurais & $\mathrm{R} \$$ & $5.159 .344,00$ & $\mathrm{R} \$$ & $5.792 .825,99$ \\
\hline Quotas em empresas & $R \$$ & $11.771 .961,44$ & $R \$$ & $1.110 .033,65$ \\
\hline Fundos de investimento & $\mathrm{R} \$$ & $79.020,06$ & $\mathrm{R} \$$ & 955,14 \\
\hline Empréstimos a $\mathrm{PJ}^{7}$ ou $\mathrm{PF}^{8}$ & $R \$$ & $11.519 .838,45$ & $R \$$ & $3.573 .539,46$ \\
\hline $\begin{array}{l}\text { Títulos voltados ao } \\
\text { entretenimento }\end{array}$ & $R \$$ & $16.265,77$ & $R \$$ & 600,25 \\
\hline TOTAL & $\mathrm{R} \$$ & $31.223 .067,22$ & $\mathrm{R} \$$ & $10.477 .981,49$ \\
\hline
\end{tabular}

Org.: PAULA, R. F. de

É possível observar na Tabela 1 dois aspectos fundamentais: a posse de propriedades rurais que, somados os valores de Agripino e Paulo Lima, ultrapassam dez milhões de reais, o que reforça o apontamento inicial de que a posse de terras é uma das bases do Grupo Lima, ou seja, propriedades que diversificaram seus capitais ao longo do tempo, o que demonstra a proximidade deste grupo aos interesses ruralistas. É importante destacar que a aquisição de propriedades rurais adquiridas pelo grupo decorre concomitante ao sucesso financeiro da UNOESTE Universidade do Oeste Paulista, que pertence, ainda, a família Lima. Cabe o realce,

\footnotetext{
${ }^{7}$ Pessoa Jurídica.

${ }^{8}$ Pessoa Física.
} 
também, aos investimentos diversificados do grupo, sendo destaque as quotas em empresas e os empréstimos realizados, ambos acima dos dez milhões de reais.

O poder econômico, aliado à posse de veículos de comunicação, coloca o Grupo Lima em uma situação segura financeira e materialmente, ao passo que se torna também uma via na qual outros agentes político-territoriais se apoiam e são apoiados ao almejarem cargos eletivos de relevante papel no poder político municipal. Além disso, atuou junto a Diocese de Presidente Prudente por vários anos, especialmente no combate ao Movimento dos Trabalhadores Rurais sem Terra (MST) no Pontal do Paranapanema e na construção de várias igrejas católicas (FELÍCIO, 2012), inclusive o Santuário Morada de Deus, local de visitação regional e turismo religioso.

Prova disso é que no pleito eleitoral de 2016 "[...] o Paulo Lima azucrinou bastante, [...] chamou todo mundo para conversar, etc, prometeu para todo mundo" (MAURO_BRAGATO_8). A respeito da candidatura seguida de desistência de seu companheiro de partido Izaque Silva, vereador desde a década de 1990 e deputado federal pelo PSDB durante o período dessa investigação, Mauro Bragato disse que após as conversas mencionadas acima, com Paulo Lima, "ele já no outro dia tinha o grupo dele fechado com o Paulo Lima” (MAURO_BRAGATO_8), porque parte dos aliados do Izaque queriam fechar com o Paulo Lima.

O Grupo dos Empresários do Transporte - GET é composto por duas famílias de empresários cujo destaque não se restringe ao âmbito local: as famílias Constantino e Lemes Soares. Este grupo de poder político que nomeamos detém significativa simbiose entre o econômico e o político, ambas as famílias já tiveram seus membros eleitos para o cargo do executivo e participam direta ou indiretamente das alianças político-partidárias do município de Presidente Prudente ao longo do período analisado.

Walter Lemes Soares Júnior foi eleito em 1977 e cumpriu mandato até 1983. Após seu governo, um representante da Terceira via assumiu o cargo do executivo, Virgílio Tiezzi (1983-1988), posteriormente, o GET volta ao poder político local através de Paulo Constantino (1989-1992).

Após o mandato de Paulo Constantino, o GET, mesmo atuando direta ou indiretamente nas demais disputas pelo poder político local, não conseguiu eleger nenhum de seus representantes diretos, como a candidata Maria Auxiliadora, que saiu das urnas derrotada por Agripino Lima em 2004. No período que antecede e também sucede aquele pleito, o GET atuou constantemente nos bastidores políticos 
e nas alianças formuladas que envolviam determinadas candidaturas, como a de Mauro Bragato em 1996.

Portanto, o GET atuou com protagonismo eleitoral no período que antecede nosso recorte temporal e também no início do mesmo, haja vista a mudança nas formas de atuação territorial deste grupo, que sai da vitrine que uma candidatura ao executivo pressupõe e passa a atuar com força nos bastidores. Volta à cena e com perspectiva mais duradoura pela candidatura de José Lemes Soares em 2016. Este já havia construído caminhos para ser candidato pelo PPS em 2012, mas não teve candidatura consolidada, como verificamos nas entrevistas com Fábio Sato e José Lemes:

Já estou preparado. Nós já estamos preparados, na verdade, nós estamos nos preparando faz 4 anos para você ter ideia, há 4 anos atrás, há 4 anos atrás eu já sabia que nessa eleição eles iam vir para cima do transporte, então estou há 4 anos me preparando para coisas que eu estou ouvindo agora (JOSÉ_LEMES_8).

José Lemes demonstrou possuir contatos que extrapolam a escala municipal e, consequentemente, podem auxiliar em sua composição política e em futuras disputas eleitorais, com apoios públicos e/ou parlamentares:

[...] aí entrei na Escola de Sociologia Política, foi lá que eu conheci primeiramente, quando eu estudava lá, o André Franco Montoro, que é filho do ex-governador do estado de São Paulo, e aí eu né, em seguida, conheci o Roberto Freire, que é do PPS, [...] aí ele me convidou para ir para o PPS, eu fui, fiquei um tempo lá né, e em seguida eu recebi um convite do meu pai para que viesse para Prudente, para aqui tentar colaborar com o transporte coletivo (JOSÉ_LEMES_1).

Percebeu-se a existência de conexões entre José Lemes e políticos com destacado papel nacional, como Roberto Freire, o que traz indícios de que José Lemes continuará presente nas disputas eleitorais, seja como candidato a deputado estadual ou ao executivo municipal. Afinal, a base material do GET proporciona conforto financeiro ao possível candidato e o mesmo detém parte de seus interesses econômicos atrelados a dinâmicas municipais devido as empresas de transporte coletivo. Falta-lhe, ainda, apesar das tentativas de diálogo, construir uma base política que envolva agentes político-territoriais da Terceira via que endossem sua candidatura. 
O GET, no qual está presente José Lemes Soares, detém base material presente em diferentes partes do país, com destaque as empresas do setor de viação, como a Andorinha, TCPP - Transporte Coletivo de Presidente Prudente, Transol Transporte Coletivo (Florianópolis - SC) e a Transpar (Campo Grande MS). A Figura 2 mostra parte das empresas pertencentes ao Grupo Lima e ao GET nos estados de São Paulo, Rio de Janeiro, Paraná e Santa Catarina (Figura 2), ilustrativo, portanto, de uma base material para além do regional de ambos os grupos, bem como sua capacidade de comando/controle de outras instituições em outros territórios.

Figura 2: Distribuição das empresas do Grupo Lima e GET nos estados de São Paulo, Rio de Janeiro, Paraná e Santa Catarina

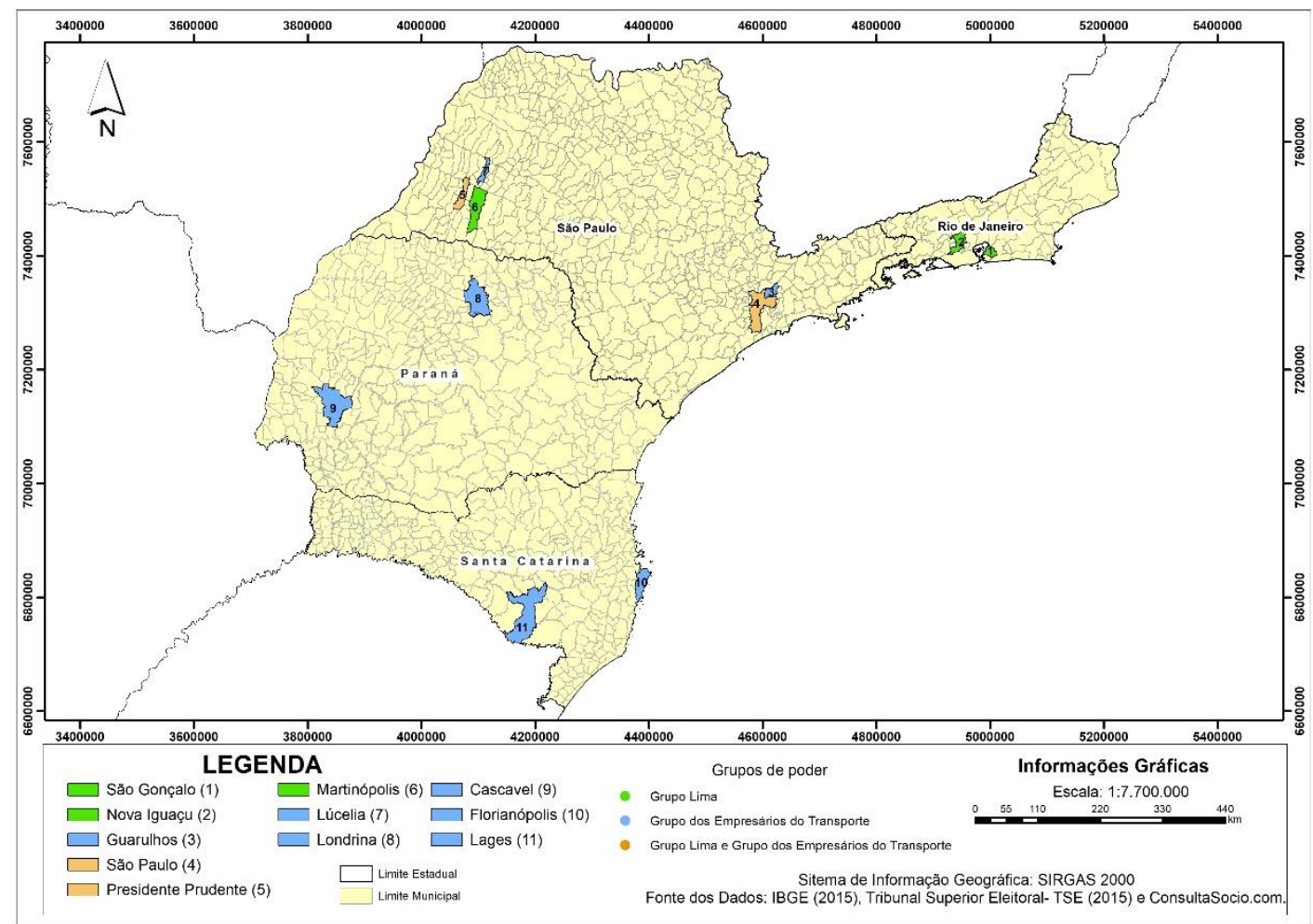

Importante se faz, ainda, a percepção de que a novidade José Lemes, que afirma fazer parte da construção de novos caminhos, pertence e representa os interesses do GET (sua base material), de uma determinada classe social e, portanto, faz parte de uma renovação das aparências que, na essência, mantém arraigado o conservadorismo político e interesses de classe do setor econômico que está vinculado.

A Figura 3 destaca vinculações mais sólidas ao longo do tempo; que demonstram alto grau de coesão entre os membros do GET e do Grupo Lima, 
detentores de menor número de agentes político-territoriais relevantes, mas que entre si demonstram harmonia, não apenas atualmente, mas ao longo recorte temporal.

Figura 3: Redes de poder dos agentes político-territoriais com alto índice de conexão ( $\geq 15$ pontos)

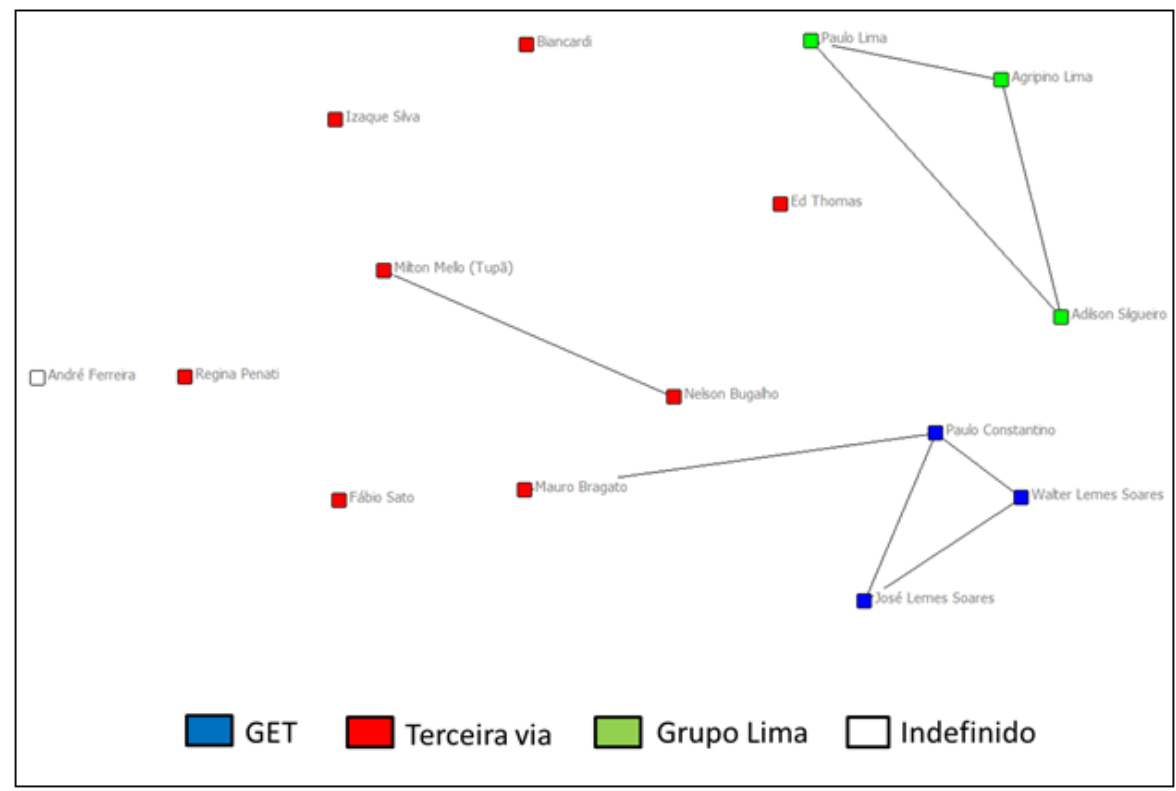

Org.: PAULA, R. F. de (2018)

As conexões de alto grau em redes menores decorrem da estratégia de ambos os grupos econômicos (Grupo Lima e GET) no que se refere a seletividade daqueles que compõem o "alto escalão" dos mesmos. Por outro lado, a falta de vinculações mais sólidas entre aqueles que compõem a Terceira via, como observamos na Figura 3, faz com que constantemente este grupo atue junto ao GET e/ou ao Grupo Lima, com destaque especial o papel do GET, que possui entrada mais recorrente junto à Terceira via devido ao elo principal que une os dois grupos: Mauro Bragato.

A única vinculação dentro da Terceira via que alcançou o status de alta é entre Tupã e Nelson Bugalho, que pertencem ao mesmo partido atualmente, sendo Tupã o principal defensor da candidatura do companheiro de partido; no entanto, ambos possuem ligação ao longo de ambos os mandatos de Tupã, pois Nelson Bugalho esteve sempre vinculado a partidos da base aliada mesmo enquanto promotor público, além da boa relação pessoal entre eles.

Considerou-se, com base nas entrevistas e dados secundários, nove membros mais importantes deste Grupo, com destaque para Mauro Bragato, Milton 
Mello (Tupã), Nelson Bugalho, Izaque Silva, Ed Thomas, Fábio Sato, Biancardi e o Partido dos Trabalhadores e sua base sindical, especialmente o Sindicato dos Bancários e Financiários de Presidente Prudente. Dentre esses agentes, temos aqueles que exercem centralidade significativa durante o recorte temporal, como Mauro Bragato e Ed Thomas, outros com centralidade crescente, como Izaque Silva e Nelson Bugalho, ou em declínio, como o PT.

Um dos fundadores do PSDB local, coordenador regional do partido e com conexões próximas ao governador do estado, de quem já foi secretário, Mauro Bragato exerceu papel relevante em todo o nosso recorte temporal: nas disputas com o Grupo Lima, especialmente na década de 1990 e início dos anos 2000, bem como nos seguidos apoios aos candidatos da Terceira via, de sua preferência, envolvendo nessas alianças Paulo Constantino, membro do GET. Afinal, a investigação demonstrou que Mauro Bragato é o principal elo da Terceira via em relação ao GET

Enquanto Mauro Bragato demonstra exercer centralidade política e uma confluência que envolve o GET, Izaque Silva e Nelson Bugalho, que possui um passado dentro do PSDB e junto ao governador do estado, Tupã mantém-se próximo do raio de atuação de Mauro Bragato, mas possui centralidade própria, mesmo que proporcionalmente mais frágil, pois dentre os agentes político-territoriais que citamos no início desse tópico, apenas Nelson Bugalho, prefeito eleito em 2016, apresenta relações mais estreitas com Tupã, o que demonstra um potencial eleitoral e de transferência de voto por parte do ex-prefeito, mas que o mesmo ainda não detém bases muito sólidas na Terceira via.

Nelson Bugalho caracteriza-se como uma força política em crescimento por ser o atual prefeito e, com isso, pode intensificar suas vinculações institucionais, que podem já ter feito a diferença para o resultado eleitoral de 2016, considerando a pequena margem de diferença de votos entre os dois primeiros colocados, de aproximadamente mil votos. O mesmo processo ocorre em relação a Izaque Silva, que assumiu o cargo de Deputado Federal em janeiro de 2016.

A atuação regional de Ed Thomas e sua participação ao longo das duas gestões do governo Tupã endossaram a importância de seu cargo enquanto deputado e auxiliaram também na eleição de vereadores do PSB, partido que emerge no contexto da Terceira via após a afirmação de Ed Thomas; portanto, discordamos da leitura feita por Mauro Bragato, quando caracteriza a força política 
de Ed Thomas como "residual" devido a sua derrota nas eleições municipais para Tupã em 2008.

Ed Thomas é um elo existente entre o Grupo Lima e a Terceria via, especialmente devido a sua relação próxima a Adilson Silgueiro, membro do Grupo Lima e também por sua gênese ligada a este grupo. Mais importante ainda é a posição de centralidade que exerce entre os agentes político-territoriais da Terceira via, como Biancardi e Fábio Sato.

$\mathrm{O}$ arranjo em rede demonstra a heterogeneidade da Terceira via, ressalta a considerável quantidade de conexões de média relevância nas redes de poder (Figura 4) e, consequentemente, tem como rebatimento o fato de que os agentes desse grupo de poder com maior grau de centralidade possuem estratégica posição nas disputas no território.

Figura 4: Redes de poder dos agentes político-territoriais com médio índice de conexão (entre 7 e 14 pontos)

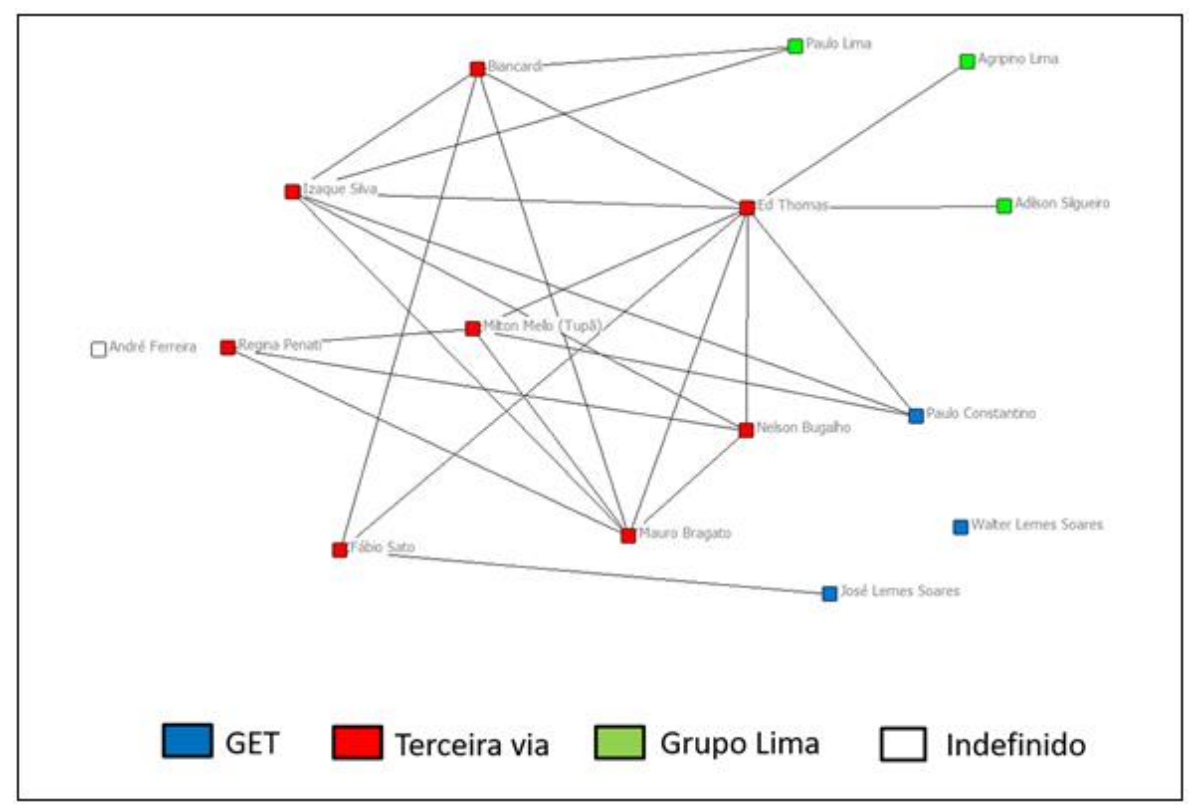

Org.: PAULA, R. F. de (2018)

É fundamental apontar a centralidade de Ed Thomas e Mauro Bragato, ambos com maior número de conexões com outros agentes político-territoriais entre aqueles que pertencem à Terceira via; afinal, neste momento, trata-se de vinculações fortes o bastante para não serem ignoradas e/ou minimizadas. Além disso, é importante ressaltar o papel de Ed Thomas e Izaque Silva como interlocutores com o Grupo Lima e que é através destes agentes que são construídas as plataformas de disputa da Terceira via. 
Ainda na Figura 4, destacam-se as conexões entre Regina Penati e Mauro Bragato, cujos partidos possuem rivalidade no cenário estadual e nacional, mas que possuem proximidade considerável devido à atuação conjunta de PT e PSDB ao longo de todo o recorte temporal, afinal, os casos em que os partidos estiveram juntos supera a quantidade de pleitos em que estiveram separados.

Por último, o PT, que atualmente não exerce de fato um papel de centralidade, pois não se vinculou a nenhum dos agentes político-territoriais da Terceira via no último pleito eleitoral. Concomitante a isso e considerando o cenário político nacional, teve como resultado o insucesso da candidatura de Regina Penati, com votos muito abaixo das expectativas de seus próprios adversários, todavia, não podemos ignorar a centralidade exercida pelo partido ao longo de todo o recorte temporal, perdendo força apenas no final deste mesmo recorte.

Na década de 1990 e início dos anos 2000 o PT foi firme oposição ao Grupo Lima, posicionando-se ao lado do PSDB de Mauro Bragato em coligações que disputavam com o Grupo Lima. Com o governo federal presidido por Luís Inácio Lula da Silva, a partir de 2003, o PT passa a ser um partido atraente para coligações em todo o Brasil (Mizuca, 2007).

No entanto, o cenário nacional adverso ao PT, que culminou na perda do mandato da ex-presidenta Dilma Rousseff, trouxe rebatimentos muito claros para as dinâmicas locais, pois as coligações que encabeçaram a disputa em 2016 sequer tentaram aproximar-se do PT, como ficou subentendido em diferentes entrevistas:

[...] eu não fiz convite para o PT, para estar comigo ou para estar com o Sato, quem sabe tenham havido conversas, mas foi muito tímido até porque não prosperou, por causa de toda essa situação realmente do país, de não querer estar perto, foi isso que aconteceu, a gente não pode ficar rodeando aqui e ali. A situação natural, que seria a mais natural, era o PT estar com o PTB do prefeito apoiando Nelson Bugalho, mas eu acho que eles não receberam o convite (ED_THOMAS_11).

A força do partido depende inexoravelmente de um desses elementos no ambiente político. O partido é interessante do ponto de vista de gestão, com boa entrada no governo estadual e/ou federal para angariar recursos, ou consegue, via militância e/ou trabalho junto a instituições diversas, obter margens de votação consideráveis e perenes, algo que o PT possuía em Presidente Prudente desde a década de 1990. 
O PT destoa do processo de reorganização dos grupos de poder ora em curso, o distanciamento estratégico de outros agentes político-territoriais do partido o leva para outro processo, ainda muito embrionário para construirmos conclusões sólidas: a aproximação com partidos mais à esquerda, como o PSOL, verificadas nas entrevistas com André Ferreira e Regina Penati.

Por outro lado, é uma possível nova frente a se confirmar ou dissipar no próximo pleito eleitoral, apesar de a origem já fragilizada em razão da: (i) rejeição ao PT, confirmada nas urnas nas eleições de 2016 por todo o Brasil, sendo o partido que saiu de posição privilegiada no número de prefeituras para a distante 13ำ colocação e; (ii) participação ainda embrionária do PSOL, que aparece recentemente no cenário partidário prudentino ainda com inexpressivos resultados eleitorais. De todo modo, temos, no período em que foi realizada essa pesquisa, um momento de grande incerteza política.

Em síntese, o processo de reorganização dos grupos de poder em curso envolve dois fatores principais, sendo o primeiro a renovação de quadros políticos em Presidente Prudente, o que não significa necessariamente uma transição de políticos idosos para políticos jovens, mas o surgimento de novos agentes políticoterritoriais envolvidos diretamente nas disputas pelo poder político local que, como foi apresentado neste artigo, detém vínculos estreitos com os grupos de poder político e econômico que destacamos, ou seja, sua essência está vinculada a convicções parelhas àquelas arraigadas no Grupo Lima e GET.

O segundo fator importante são outras duas faces da reorganização, uma ocorre no seio de cada um dos grupos investigados, como a emergência protagonista de José Lemes Soares como membro familiar no GET; outra, dá novo ordenamento nas relações intergrupos de poder, cujas relações em rede nos indicaram centralidades e agentes dependentes. Tal configuração detém impactos territoriais, considerando a ação das instituições de classe e dos movimentos sociais, de modo que a reorganização em curso exclui ainda mais a sociedade civil organizada, ao passo que se vincula a estruturas econômicas de relevância regional e nacional.

Fábio Sato e sua aproximação cada vez maior com agentes político-territoriais com gênese no Grupo Lima, assim como Tupã que, após seu distanciamento em relação ao Grupo Lima construiu sua base de apoio com empresários locais e a partir de agentes político-territoriais que outrora pertenceram ao seu antigo grupo, 
indicam que a essência política de ambos se mantém vinculada a valores e posicionamentos semelhantes às suas raízes.

Após a discussão a respeito dos três grupos de poder identificados nessa pesquisa, estão sintetizadas suas estratégias na Figura 5 , destacando as principais estratégias e ações utilizadas pelos grupos de poder no intuito de reproduzirem-se social e politicamente.

Figura 5: Ações e estratégias utilizadas pelos grupos de poder em Presidente Prudente - SP

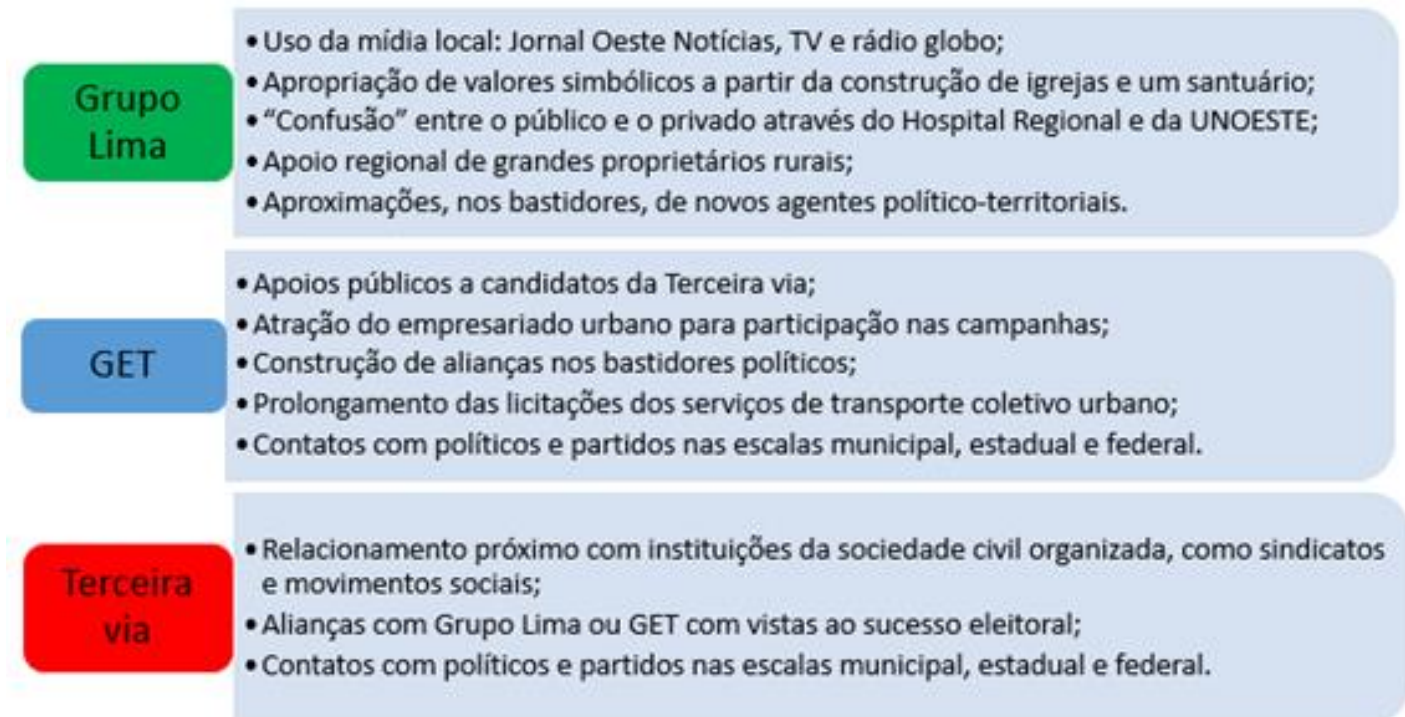

Alguns aspectos explicados por Silva (2007) a respeito da formação dos territórios conservadores de poder são pertinentes para a análise do Pontal do Paranapanema e, por conseguinte, para o entendimento das estratégias verificadas na Figura 5 pelos grupos de poder em Presidente Prudente, são eles: (i) a histórica concentração fundiária, que induz o conflito agrário no pontal há décadas, ainda que os processos que levaram a essa concentração sejam distintos (as sesmarias no centro-sul do Paraná e o mercado ilegal de terras devolutas no Pontal); (ii) a dinâmica econômica vinculada à pecuária extensiva (algo característico da formação territorial do Pontal); (iii) a política vinculada a práticas conservadoras, personalistas e o poder familiar ligado à posse da terra, considerando os dois últimos aspectos muito característicos dos dois principais grupos de poder identificados e investigados nessa pesquisa, o Grupo Lima e o GET; e (iv) a monocultura ou culturas de exportação que ampliam o latifúndio e mantém a estrutura agrária que, no caso do Pontal do Paranapanema, está representado na grande produção canavieira voltada ao açúcar (mercado interno e externo) e ao etanol. 


\section{Considerações Finais}

Verificou-se as estratégias e ações dos grupos de poder através de dados secundários como os resultados eleitorais, despesas e receitas de campanha, bem como por meio das entrevistas que forneceram os indícios necessários para evidenciar as estratégias colocadas anteriormente (Figura 5) e, ainda, identificar um processo de reorganização em curso e sua relação com a formação e sustentação dos territórios conservadores de poder (SILVA, 2007). É importante ressaltar que a atuação destes grupos se vincula ao território, faz uso do mesmo e gera rebatimentos sociais, econômicos e políticos.

A análise das relações de poder e das conexões entre os agentes políticoterritoriais a partir das redes permitiu observar a centralidade atual exercida por Ed Thomas, Mauro Bragato e Milton Mello (Tupã) na Terceira via, de um lado, e a perda de centralidade do Partido dos Trabalhadores, de outro. É fundamental reafirmar que consideramos a Terceira um grupo heterogêneo, caracterizado inicialmente pela oposição aos grupos de poder tradicionais no período que antecede o recorte temporal. O momento de maior coesão desse grupo diz respeito ao pleito eleitoral na qual saiu vitorioso Mauro Bragato, em 1996.

A conjuntura atual de mudanças nas formas de ação dos grupos de poder e a sua configuração em redes de poder aponta para continuidades e descontinuidades nas alianças entre os agentes político-territoriais que compõem os três grupos de poder nomeados. O fundamental é que a partir dessa conjuntura, que também partiu de outra, se construirão novas disputas e, consequentemente, outros rebatimentos territoriais.

A configuração das redes de poder irá influenciar alianças, conflitos e os interesses que irão sobressair nas próximas administrações. A reorganização em curso, fomentada pelas redes, também sustenta os territórios conservadores de poder no Pontal do Paranapanema, pois é um processo político, econômico e social que restringe as aspirações populares mesmo nas disputas eleitorais, tornando desiguais as condições materiais das candidaturas observadas ao longo do recorte temporal, de modo que algumas dispõem de estrutura e financiamentos muito superiores a outras.

Por meio dessa pesquisa, em síntese, foram constatados os grupos de poder que atuam em Presidente Prudente, identificou-se suas ações e estratégias, investigou-se as respectivas bases materiais dos grupos e foram observados os 
apoios político-econômicos, com destaque àqueles oriundos do capital privado. Finalmente, mensurou-se o grau de conexão entre os agentes político-territoriais nas redes de poder, classificando-as em níveis distintos e destacando as centralidades crescentes e decrescentes, com vistas a leitura geográfica das disputas que emergem no território.

\section{REFERÊNCIAS}

AUGUSTO, D.; SILVA, M. "Revelando" grupos de poder político nas páginas de jornais locais. Revista Percurso, n. 11, p. 110-126, 2014.

BOURDIEU, P. O poder simbólico. Rio de Janeiro: Bertrand Brasil, 1989.

CASTRO, I. E. de et al. Geografia: conceitos e temas. Rio de Janeiro: Bertrand Brasil, 1996. CASTRO, I.E. Geografia e política: território, escalas de ação e instituições. Rio de Janeiro: Bertrand Brasil, 2005.

CASTRO, I.; RODRIGUES, J.; RIBEIRO, R. Para o encontro da geografia com a democracia. In: Espaços da democracia. Rio de Janeiro: Bertrand Brasil, 2013,

p.11-20.

CASTRO, I. E. Do espaço político ao capital social. O problema da sobre-representação legislativa nos municípios pequenos. Redes, v. 12, n. 2, p. 56-72, 2008.

FELÍCIO, M. J. Ação pastoral e questão agrária no Ponta do Paranapanema. Revista Nera, Presidente Prudente, n. 7, p. 112-124, 2012.

FERNANDES, B. M. Construindo um estilo de pensamento na questão agrária: o debate paradigmático e o conhecimento geográfico. 2013, 343f. Tese (Livre docência) Faculdade de Ciência e Tecnologia, Universidade Estadual Paulista, Presidente Prudente. GINZBURG, C. Mitos, emblemas, sinais. São Paulo: Companhia das Letras, 1989. HAESBAERT, R. Da desterritorialização à multiterritorialidade. Boletim Gaúcho de Geografia, Porto Alegre, v. 29, n.1, p. 11-24, jan 2003.

KERBAUY, M.T.M. A morte dos coronéis: política interiorana e poder local. São Paulo: PUC, 1992. Tese (Doutorado) - Faculdade de Filosofia, Ciências e Letras, Pontifícia Universidade Católica de São Paulo, São Paulo.

KERBAUY, M. T. M. Federalismo, descentralização e democracia. Estudos de Sociologia, v. 6, n. 10, 2007.

KINZO, M. D. Os partidos no eleitorado: percepções públicas e laços partidários no Brasil. Associação Nacional de Pós-Graduação e Pesquisa em Ciências Sociais, 2005.

KINZO, M. D. Partidos, eleições e democracia no Brasil pós-1985. Associação Nacional de Pós-Graduação e Pesquisa em Ciências Sociais, 2004.

LEITE, J. F. A ocupação do pontal do Paranapanema. São Paulo: Hucitec, 1998. MIZUCA, H. D. de. Coligações em eleições majoritárias municipais: a lógica do alinhamento dos partidos políticos brasileiros nas disputas de 2000 e 2004. 2007. 176 f. Tese (Doutorado) - Universidade de São Paulo. São Paulo.

PERES, P. S. Comportamento ou instituições? a evolução histórica do neo-institucionalismo da ciência política. Revista Brasileira de Ciências Sociais, v.23, n.68, out., 2008.

RAFFESTIN, C. Por uma geografia do poder. 29.ed. São Paulo: Ática, 1993.

REIS, F. W. Governabilidade, instituições e partidos. Novos Estudos Cebrap, v. 41, p. 4059, 1995.

RODRIGUES, L. M. Eleições, fragmentação partidária e governabilidade. Novos Estudos, v. 41, p. 78-90, 1995.

RÜCKERT, A. A. Reforma do Estado, reestruturações territoriais, desenvolvimento e novas territorialidades. GEOUSP - Espaço e Tempo. São Paulo, n. 17, p. 79-94, 2005.

SANTOS, M. A natureza do espaço: técnica e tempo, razão e emoção. 4 ed. São Paulo: Editora da Universidade de São Paulo, 2014. 
SANTOS, M; SILVEIRA, M. L. A questão: o uso do território. In:

O Brasil: território e sociedade no início do século XXI. 9 ed. Rio de Janeiro: Record, 2006, p.19-22.

SILVA, M. O poder local em Presidente Prudente -SP: o comerciante e suas representações sociais. 2000. 169 f. Dissertação (Mestrado) - Faculdade de Ciências e Tecnologia, Universidade Estadual Paulista, Presidente Prudente.

SILVA, M. Análise política do território: poder e desenvolvimento no centro-sul do Paraná. Guarapuava: Unicentro, 2007.

SILVA, M. O centro-sul do Paraná: poder, governos locais e as relações com o Mercosul.

Caderno Prudentino de Geografia, Presidente Prudente, n.34, v.2, p.4-26, ago./dez. 2012. SILVA, M. Poder local, ideologias e representações sociais. Mercator, Fortaleza, v. 13, n. 2, p. 39-51, mai./ago. 2014.

SOUZA, M. J. L. O território: sobre o espaço e poder, autonomia e desenvolvimento. In: CASTRO, I. E. et al. Geografia: conceitos e temas. Rio de Janeiro: Bertrand Brasil, 2012. p. 77-116.

VAINER, C. B. As escalas do poder e poder das escalas: o que pode o poder local? In: ENCONTROS NACIONAIS DA ANPUR, 9. Belo Horizonte. Anais... Belo Horizonte, v. 9, 2001.

WEBER, M. Ciência e política: duas vocações. São Paulo: Cultrix, 1968.

\section{NOTAS DE AUTOR}

\section{CONTRIBUIÇÃO DE AUTORIA}

Rafael Freire de Paula - Conceituação; Investigação; Coleta de dados; Análise de dados; Elaboração do manuscrito.

Márcia da Silva - Supervisão; Análise de dados; Participação ativa da discussão dos resultados; Revisão e aprovação da versão final do manuscrito.

\section{FINANCIAMENTO}

CNPq Edital Pesquisa Básica e Aplicada.

\section{CONSENTIMENTO DE USO DE IMAGEM}

Os participantes da pesquisa consentiram, via documento escrito e assinado, a divulgação dos dados e das informações coletadas.

\section{APROVAÇÃO DE COMITÊ DE ÉTICA EM PESQUISA \\ Não se aplica.}

\section{CONFLITO DE INTERESSES}

Não se aplica.

\section{LICENÇA DE USO}

Este artigo está licenciado sob a Licença Creative Commons CC-BY. Com essa licença você pode compartilhar, adaptar, criar para qualquer fim, desde que atribua a autoria da obra.

\section{HISTÓRICO}

Recebido em: 16-11-2018

Aprovado em: 24-05-2019 